\title{
Evaluation of Dento Facial Vertical Dimension in Class II Division 1 Malocclusion after Premolar Extraction
}

\author{
Elih $^{1}$, Bergman Thahar ${ }^{2}$, Eky S. Soeria Soemantri $^{3}$, Hermawan Nagar Rasyid $^{4}$ \\ ${ }^{1}$ Orthodontic Departement, Faculty of Dentistry, University of Padjadjaran, Bandung - West Java Indonesia
}

\begin{abstract}
Introduction: The Purpose of this study was to evaluate dentofacial vertical dimension alteration in patients with class II division 1 malocclusion after the first maxillarypremolar extraction. Methods:This study used 24 cephalogramseach before and after treatment. Dentofacial dimension measured by Sivakumar and Valiathan method. The cephalometric measurements investigated were as follows : mandibular plane angle, anterior facial height, lower anterior facial height, posterior facial height, facial height indeks, FH-U1, FH-U6, FL-L1, Fl-L6, $S_{\text {vertical }}$ U1, $S_{\text {vertical }}$ U6, Pog $_{\text {vertical }}$ L1, Pog vertical $_{\text {L6. }}$ To determine dento facial vertical dimension changes due to treatment paired t-test were performed, respectively. Results: There was no change in the vertical dimension of dento-skeletal significantly between before and after treatment except on the posterior facial height,FL-L1, and $S_{\text {vertical }}$ U1. Conclusion: The results showed that in patients treated with extraction of two premolars, there was a significant decrease in following cephalometric measurement: the posterior facial height, FL-LI and $S_{\text {vertical }} U 1$.
\end{abstract}

Keyword: Class II division 1, dentofacial vertical dimension, premolar extraction

\section{Introduction}

The Goal of orthodontic treatment is to improve the patient's life by enhancing dental and jaw function and dentofacial aesthetics, with healthy periodontal tissue, and the function of the temporomandibular must be maintained [1][3].Extraction of premolars as practical from of orthodontic therapy has been accepted for many years, but there remains a controversy regarding the effect of premolar extraction on the facial dimension. Supposedly, extraction provides some vertical reduction. The indications for the first premolar extraction are usually severe anterior crowding or protrusion, most of the extraction space is use for alleviating crowding and retracting incisors [4]. Maxillary premolar extraction is the first choice in orthodontic treatment plan camouflage Class II division 1 at adultspatient, followed by retraction of incisor teeth to correct the inclination angle of the anterior teeth, prostrusif or to decrease the height of the vertical face. Treatment with mandibular retraction often causes rotation anti clockwise, causing a decrease in the vertical dimension [5].

The incisolabial relationship may undergo appreciable changes after treatment, not only as a result of craniofacial growth and development, but also because of orthodontic procedures adopted, such as extraction, retraction of maxillary incisors, as well as the use of intermaxillary elastic and extraoral appliances [6]. Vertical dimension changes that occur in the orthodontic treatment of malocclusion Class II division 1 is an important thing to be considered for extrusion or intrusion of the teeth can affect the aesthetic and the temporomandibular joint. Wyatt claimed that premolars extraction followed by retraction of anterior teeth on orthodontic treatment with Class II division I can cause the displacement of the condyle to the posterior and anterior discus displacement. Vertical dimension changes can affect the aesthetic smile, this was due to the change in position of the maxillary molar teeth, the inclination of the occlusal plane, and the direction of kraniofasial growth [6].
During this time it is debatable whether premolar extraction will affect the changes in the vertical dimension or not. Cusinamo et al, indicated that premolar extraction does not result in decreasing the facial height [4].Al Nimri et al study results proved that an increase in anterior facial height, lower anterior facial height, posterior facial height in the treatment of Class II division I with extraction of two The first maxillary premolar and two the second maxillary premolars [7] .Some studieds demonstrated increases in the absolut values of anterior and posterior facial height, even with premolar extraction with no futher in the mandibular plane angle (MPA) [8],[9]. Based on the above description researchers interested in conducting research on changes in the vertical dimension to the treatment of dento-facial malokusi class II division I use a fixed appliance with two the first maxillary premolars extraction.

\section{Material and Methods}

The Samples were taken from all patients with Class II division I, which had been treated at the Orthodontic Postgraduate Programme Clinic, Orthodontics Faculty of Dentistry University of Padjadjaran. Twenty-four lateral cephalometric radiographs before and after selected with the following criteria: (1) The age of patients was more than 15 years. (2) Gender male and female, (3) patients have medical records, study model, lateral cephalometric radiographs before and after treatment. (4) Class II division I malocclusion. (5) Treatment compromise edgewise technique with two the first maxillary premolar extraction.

Cephalometric tracing is done manually with calibration intra etraminer on transparent acetate paper. A reference point in this study are: Nation (N), Sella tursica (S), Menton (Me), Artikulare (Ar), Gonion (Go), pogonion (Pog), Gnation (Gn), Spina nasalis anterior (SNA), posterior Nasal Spine (PNS). The reference lined used were palatal plane (ANS-PNS), Frankfort horizontal (FH), Mandible plane(G0$\mathrm{Gn})$, and the mandibular fiduciary line (FL). FL was drawn

Volume 5 Issue 6, June 2016 www.ijsr.net 


\section{International Journal of Science and Research (IJSR) \\ ISSN (Online): 2319-7064}

Index Copernicus Value (2013): 6.14 | Impact Factor (2015): 6.391

between 2 fiduciary points. The fiduciary points were arbitrarily located below the lower border of mandible and approximately parallel to the occusal plane.

Lines and angles to measure the skeletal vertical dimension according to the Sivakumar and Valiathan method: mandibular plane angle is the angle formed by the mandibular plane (Go-Me) with frankfrot horizontal (FH) plane. Anterior facial height (N-Me), Lower anterior facial height (ANS- Me), Posterior facial (S-Go). High index faces is a high ramus divided distance from menton to palatal plane (fig. 2).A coordinate system with the FH plane and a perpendicular line through sella $\left(S_{\text {vertical }}\right)$ was used for measureing maxillary molar and incisor position. Mandibular molar and incisor position were measured from a perpendicular to the FL line tangent to pogonion: Pog $_{\text {vertical }}$ (fig 3.) [10].The cephalometric measurement used in this study are described in table 1 .

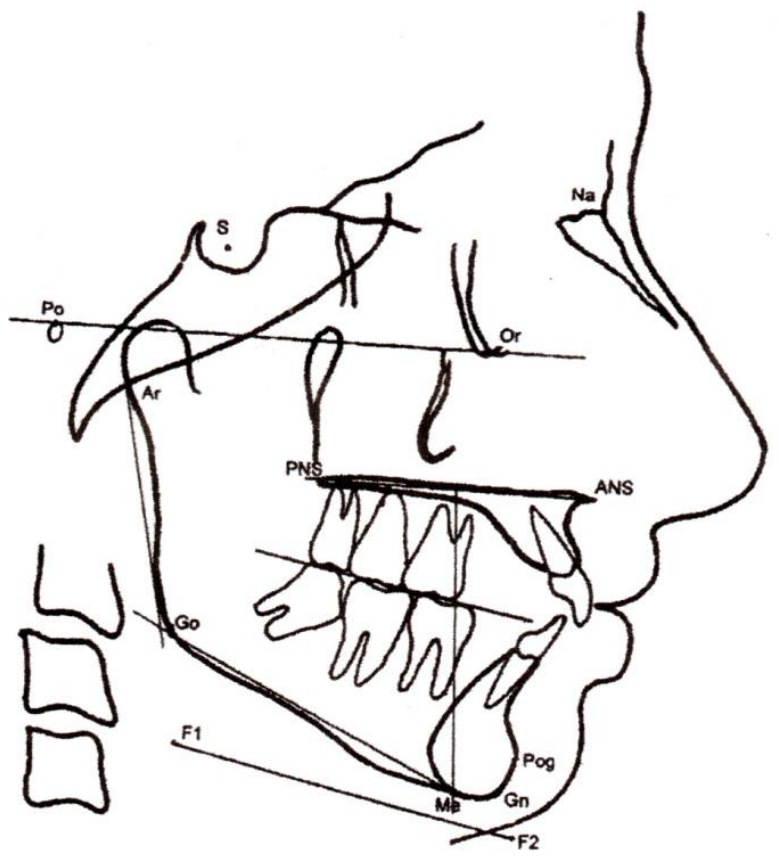

Figure 1: Lateral cephalometric landmark and measurements.

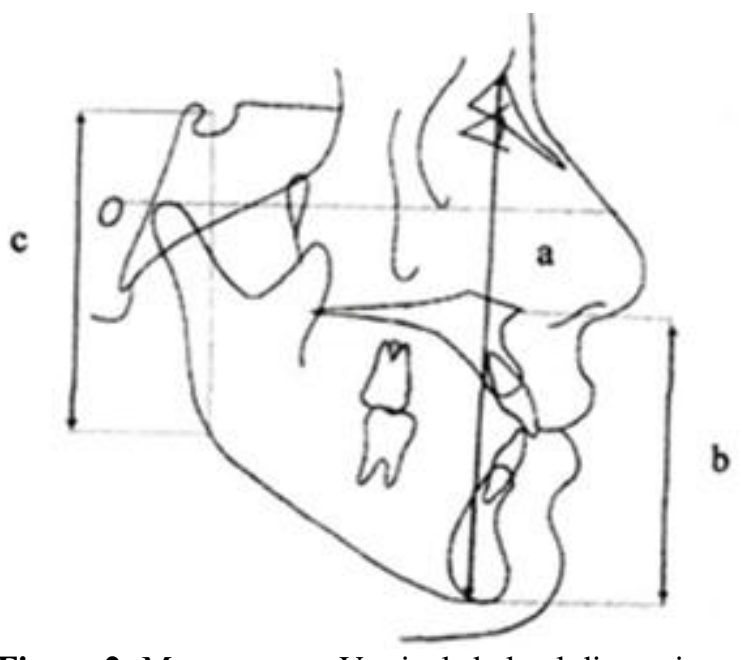

Figure 2: Measurement Vertical skeletal dimensions

a. Anterior facial height (N-Me). b. Lower anterior facial height (ANS-Me). c. Posterior facial height (S-Gn)

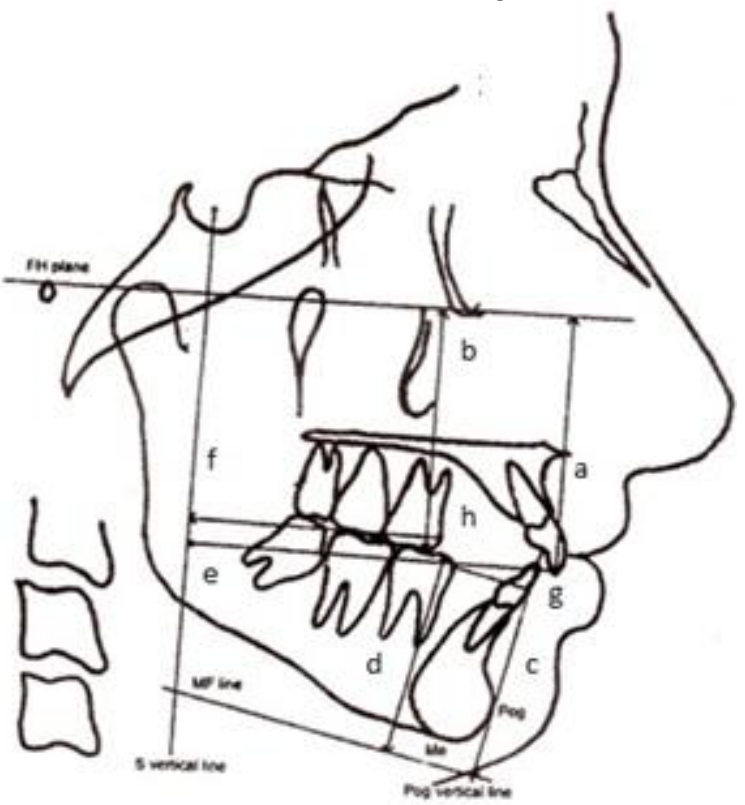

Figure 3: Linear measurements with overall and mandibular coordinate system. a.FH-U1 , b. FH-U6. c. FL-L1. d. FL-L6 -M1 e. $S_{\text {vertical }}$ U1. f. $S_{\text {vertical }}$ U6.

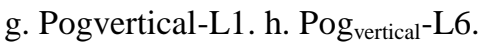

Table I: Definition of linear and angular measurements

\begin{tabular}{|c|c|}
\hline Anterior facial height (AFH) & Linear distance between nasion and menton $(\mathrm{Me})$ \\
\hline Lower anterior facial height (LAFH) & Linear distance between the anterior nasal spine and $\mathrm{Me}$ \\
\hline Posterior facial height $(\mathrm{PHH})$ & Linear distance between Sella (S) and Gonion (Go) \\
\hline Facial height index (FHI) & Ramus height divided by the distance from Me measured to the palatal plane \\
\hline FH-U $\mathrm{U}_{1}$ & Perpendiculardistance from the Frankfort horizontal $(\mathrm{FH})$ plane to incisal edge of the maxillary incisor \\
\hline $\mathrm{FH}-\mathrm{U}_{6}$ & Perpendicular distance from FH plane to mesiobuccal cups tip of the maxillary first molar \\
\hline FL-L ${ }_{1}$ & Perpendicular distance from the fiduciary line (FL) to the incisal edge of the mandibular incisor \\
\hline FL-L 6 & Perpendicular distance from the FL to the mesiobuccal cusp tip of the mandibular first molar \\
\hline $\mathrm{S}_{\text {vertical }}-\mathrm{U}_{1}$ & Perpendicular distance from S vertical to the incisal edge of maxillary incisor \\
\hline $\mathrm{S}_{\text {vertical }}-\mathrm{U}_{6}$ & Perpendicular distance from $\mathrm{S}$ vertical to the mesial convex point of the maxillary first molar \\
\hline Pog $_{\text {vertical }} \mathrm{L}_{1}$ & Perpendicular distance from Pogonion (Pog) vertical to the incisal edge of the mandibular incisor \\
\hline $\mathrm{Pog}_{\text {vertical }} \mathrm{L}_{6}$ & $\begin{array}{l}\text { Perpendicular distance from Pogonion (Pog) vertical to the mesial convex point of the mandibular first } \\
\text { molars }\end{array}$ \\
\hline MPA & Angle formed by the mandibular plane (G0-Me) and FH plane \\
\hline
\end{tabular}

Evaluation of dentofacial vertical dimension changes before and after treatment in Class II division use Sivakumar and Valiathan methods, performed statistical tests to test the data using a paired $\mathrm{t}$ statistic. $\mathrm{P}$ values less than .05 were considered significant.

\section{Volume 5 Issue 6, June 2016} www.ijsr.net 
International Journal of Science and Research (IJSR)

ISSN (Online): 2319-7064

Index Copernicus Value (2013): 6.14 | Impact Factor (2015): 6.391

\section{Results}

Tabel II: Comparison of pretreatment and postreatment measurement

\begin{tabular}{|c|c|c|c|c|c|}
\hline \multirow{2}{*}{ Parameter } & \multicolumn{5}{|c|}{$\mathrm{n}=24$} \\
\cline { 2 - 6 } & Before & After & Difference & SD & P value \\
\hline MPA ( $)$ & 31.63 & 32.21 & 0.58 & 2.52 & 0.099 \\
\hline Anterior facial height (AFH) & 12.16 & 12.56 & 0.40 & 2.5 & 0.206 \\
\hline Lower anterior facial height (LAFH) & 68.13 & 66.38 & 1.75 & 3.35 & 0.099 \\
\hline Posterior facial height (PHH) & 76.56 & 73.96 & 2.60 & 4.07 & $0.005^{*}$ \\
\hline Facial height index (FHI) & 1.12 & 1.13 & 0.01 & 0.045 & 0.681 \\
\hline FH-U & 55.42 & 55 & 0.42 & 3.56 & 0.731 \\
\hline FH-U & 50.15 & 48.21 & 1.94 & 4.81 & 0.061 \\
\hline FL-L $_{1}$ & 41.79 & 39.79 & 2.00 & 2.59 & $0.009^{*}$ \\
\hline FL- $_{6}$ & 39.02 & 37.81 & 1.21 & 3.27 & 0.321 \\
\hline $\mathrm{S}_{\text {vertical }}-\mathrm{U}_{1}$ & 73.77 & 67.96 & 5.81 & 5.99 & $0.001^{*}$ \\
\hline $\mathrm{S}_{\text {vertical }}-\mathrm{U}_{6}$ & 45.48 & 46.33 & 0.85 & 7.34 & 0.574 \\
\hline Pog $_{\text {vertical }}-\mathrm{L}_{1}$ & 7.48 & 6.85 & 0.63 & 2.18 & 0.087 \\
\hline Pog $_{\text {vertical }}-\mathrm{L}_{6}$ & 17.46 & 18.25 & 0.79 & 2.09 & 0.240 \\
\hline
\end{tabular}

Note: * significant $(\mathrm{P}<0.05)$

On average, standard deviation, and $p$ value for cephalometric measurements listed in Table II. The height of the posterior face, FL- $\mathrm{L}_{1}$, horizontal distanceSvertikal -U1 showed a significant difference ( $\mathrm{p}, 0.05)$. On the other measurements showed no significant differences. Posterior facial height decreased by $3.85(\mathrm{p}=0.005)$, FL-L $\mathrm{L}_{1}$ decreased by 2.75 ( $\mathrm{p}=0.009$ and the horizontal distance Svertikal - U1 showed a decreased by $6.81(\mathrm{p}=0.01)$. The evaluation results of orthodontic treatment in class malocclusion II division 1 with the extraction of two the first maxillary premolar showing that the premolar extraction does not cause a decrease in the vertical dimension.

\section{Discussion}

The purpose of this study to evaluate the vertical dimension changes before and after treatment of Class II division 1 with the extraction of two the first maxillary premolars. In most cases the extraction space is used to relieve crowding, and retract the anterior teeth. When the anterior teeth retracted necessary to maintain proper anchoring posterior teeth. If anchorage can be maintained, mesial movementof the posterior tooth could be prevented or the movement is minimal so loss of vertical dimension cannothappen [11].Vertical alteration that occur in the maxillary in the vertical dimension is very important to be considered in the orthodontic treatment due to changes in the vertical dimension can be a factor etiology of temporomandibular joint disorder [12].

Mandibular growth patterns can affect the vertical dimension in patients aged growth. For this reason, the study sample consisted of patient who have completed a period of growth that is patient at the age of 15 years and above.In addition, the use of extra-oral appliance such as head gear can also affect the vertical dimension thereforein this study performed in patients receiving orthodontic treatment without the use of extra-oral anchorage appliance and functional appliance.

The results of this study prove that there was no significant difference in the measurement of the dimensions except at posterior facial height,Svertikal - U1 and FL-1 decreased significantly. The mandibular and maxillary molar showed intrusion not significanly in variable FH-U6 and FL-L1. This movement can be consequentto the mechanotherapy. In this study, a slight increase occured in variable Svertical-U6, but the changes were not significantly.This is because a small amount of mesial drifting of the maxillary molar might be allowed, depending on the severity of the anterior discrepancy [13],[14]. This study had statiscally significant differences for the variables Svertikal - U1 and FL-1, this was consequent to greater decreases in these variables because retraction of maxillary incisors and mechanotherapy during orthodontic treatment.

The results of this study are not consistent with the theory that the first premolar extraction on the orthodontic treatment can cause a decrease in the vertical dimension, which then can cause TMJ problems as reported some study [12].This research is in accordance with previous studies Kim that there was no significant change in the vertical dimension in the treatment of Class I either with or without retraction [4]. Cusinamo et al stated that there is no difference between high and low face before and after treatment in patients hiperdivergen with premolar tooth extraction.

Kyun Kim et al based research states that there is no reduction in the vertical dimension in orthodontic treatment with Class I to extraction the first premolars and the second premolars [4] . However Souto et al study results regarding changes in the vertical dimension in patients with Class II division I in pediatric clinics UNICID Brazil prove that there is a significant change in the vertical position of maxillary central incisor teeth (is-PP), the vertical position of the maxillary first molar (ms-PP), and the angle sn-palatal plane [6].Similarly, in another study proved that the treatment of malocclusion Class II Division I on the extraction of the two first premolars or two second premolar generate increased anterior facial height, lower anterior facial height and posterior facial height [7].In this study, the position of the posterior teeth can be maintained until the vertical dimension decrease does not occur. This can be seen in cephalometric 


\section{International Journal of Science and Research (IJSR) \\ ISSN (Online): 2319-7064}

Index Copernicus Value (2013): 6.14 | Impact Factor (2015): 6.391

measurements (Table 1). The results of this study indicate that the first premolar tooth extraction does not cause a decrease in the vertical dimension corresponding to that found by the Staggers and the others. [4],[12],[13].

\section{Conclusion}

According to the results of the presentstudy, it was observed that in patients with class II division I malocclusion submitted to orthodontic treatment with premolars extraction, the variable the posterior facial height, FL-LI and Svertical-U6 were shown to be significantly decrease in the post treatment evaluation.

\section{References}

[1] Bishara, S.E. "Textbook of Orthodontics", Philadelphia. W.B. Saunders Co, pp 416-417,2007.

[2] W.R.Proffit." The Orthodontics Problem" in Contemporary Orthodontics, W.R.Proffit, H.W. Field and D.M. Server, Mosby Inc., St Louis, pp 2-5,2007.

[3] J.L.Ackerman, T Nguyen and W.R.Proffit,"The decision-Making Process in Othodontics"in Orthodontics Current Principles and Techniques. L.W. Graber, R.L. Vanarsdall and K.W.L.Vig (eds),Fifth edition. Elsevier.Philadelphia, pp. 59-64, 2012.

[4] T.K.Kim, J.T.Kim, M.James, W.S Yan., S.H Baek., "First or Second Premolar Extraction Effectson Facial Vertical Dimension," The Angle Orthodontist.LXXV (2),pp.177-182,2005.

[5] A.H.Zafarmand.,M.M.Zafarmand. Premolar Extraction in Orthodontics: Does it have any effect on patient"s facial height? Vol 5,pp.64-68,2015.

[6] M.Souto, P.M.Maeda, H.J.Scavone, R.I.Ferreira, F.V. Ferreira," Vertical Cephalometric Changes after Treatment of Class II Division 1 Malocclusion". Revista de Odontologia da UniveridadeCidade de Sao Paulo. 20(1),pp.6-13, 2008.

[7] K.S. Al Nimri,"Vertical Change in Class II division1 Malocclusion after Premolar Extractions," The Angle Orthodontics. LVX (1) ,pp.52-58,2006.

[8] S.E. Bishara, D Commins, JR Jakobsen., A.R.Zaherb., Dentofasial and soft tissue changesin clss II division 1 cases treated with and without extraction Am J. Orthod Dentofacial Orthop.(107) : 28-37,1995.

[9] S.L.Taner, N.Darendeliler "The influence of extraction orthodontic treatment on craniofacia structures": evaluation according to two different factors. Am J Ortdod Dentofacial Orthop (115), pp.508-14.1999.

[10] A.Sivakumar, Ashima V., "Cephalometric assessment of dentofacial vertical changes in class I subject treated with and without extraction. ." Am J Ortdod Dentofacial Orthop;133:869-75), 2008.

[11]I. Kocadereli I, " The effect of first premolar extraction on vertical dimension.",AmJ OrthodDentofacialOrthop(116)pp.41-5.1999.

[12] J.A.Staggers, "Vertical control changes following firdt premolar extractions", Am J OrthodDentofacial Orthod.105,pp.19-24,1994.

[13] S.M. Hayasaki, J.F.C.Henriques, G.Janson and M.R. Freitas, "Influence of extraction and nonextraction orthodontic treatment in Japanese-Brazilians with Class
I and Class II division 1 malocclusions", Am J

OrthodDentofacialOrthod. 127, pp. 127-130, 2005.

Volume 5 Issue 6, June 2016 www.ijsr.net 